\title{
Teaching
Methods
}

\section{Comparison of Time Investment in Common Teaching Practices among Three Instructional Methods}

\author{
Cynthia B. McKenney ${ }^{1,4}$, Ellen B. Peffley ${ }^{2}$, and Igino Teolis ${ }^{3}$
}

\begin{abstract}
ADDITIONAL INDEX WORDS. asynchronous communication, distance education, online instruction, student contact

SUMMARY. Increasingly more collegiate courses are offered through a variety of distance formats. Course management platforms have reduced the faculty time required to create and deliver distance courses while enhancing asynchronous communication. In this study, the transactional distance theory was used to evaluate the different communication levels found between faculty and students in webfacilitated, online, and interactive video courses. A comparison of the online course sections to the web-facilitated course sections determined that there were significantly more asynchronous contacts with the online sections than with the webfacilitated sections. In addition, the total instructor time invested to administer the online course sections was significantly less than for the web-facilitated course sections. The interactive video conferencing sections could not be compared directly to the other teaching modes because the course content differed; however, mean time intervals for teaching and administrative activities are provided.
\end{abstract}

$\mathrm{O}$ ver the past few years, distance education has continued to explode in growth. Many land grant universities have implemented distance learning courses at their research and extension centers in an effort to increase distance learning enrollments (Herrington, 2006; Powell et al., 2008) A recent national survey of online instruction found over 3 million students enrolled in at

\footnotetext{
Department of Plant and Soil Science, Texas Tech University, Lubbock, TX 79409

This work was funded in part by a USDA Higher Education Challenge Grant No. 9703842.

Texas Tech University as manuscript no. T-4-541.

${ }^{1}$ Associate Professor.

${ }^{2}$ Former Professor

${ }^{3}$ Former Graduate Research Assistant.

${ }^{4}$ Corresponding author. E-mail: cynthia.mckenney@
} ttu.edu. least one online course during the Fall 2006 term (Allen and Seaman, 2007). This represents $20 \%$ of all higher education students in the United States and an almost 10\% increase from 2005. In addition, the $10 \%$ increase in online course enrollment exceeds the $1.5 \%$ growth found in higher education overall.

When these statistics are reviewed, it brings up the question: What constitutes a distance education course? Many institutions of higher education, as well as coordinating boards, define distance courses differently, but usually they include some of the following methods of distance course delivery: online instruction, interactive video conferencing (IVC), blended or hybrid courses, and mixed methods (Bray et al., 2007). For this discussion, the Sloan Consortium definition for online courses will be used (Allen and Seaman, 2007). A traditional course is delivered orally or in writing and has no form of distance technology. A web-facilitated course has $1 \%$ to $29 \%$ of the course offered online, such as a syllabus or posted assignments, but still is primarily a face-to-face course. An online course is one in which at least $80 \%$ of the content of the course is provided online and typically has no face-to-face courses. Students may be located on or off campus. In addition, for this study, IVC courses shall be those courses in which all course content is provided over IVC and the students are at a different location than the instructor with the ability to communicate synchronously.

There are numerous advantages to using distance technology for classroom instruction, including access to courses offered at only a limited number of campuses (Paulsen et al., 1998; Powell et al., 2008), addressing the needs of nontraditional students who are working heads of households, and providing a greater depth and breadth to available course programming (Bray et al., 2007). However, there are several important barriers to implementing effective distance education programs and time is at the top of the list. Most surveys have shown that release time/workload adjustment to develop the new courses is necessary (Butler and Sellbom, 2002 Wilson, 2001). Additional faculty time is needed to participate in technology training and in the actual use of the new technology in developing course materials. While estimates for course preparation time vary, the concern is very real. Course management platforms provide tools to help reduce faculty time by automating tasks such as grading and delivering course content. Faculty time required for distance course development, preparation, and delivery may be distinctly different from the time necessary for similar tasks with a traditional course. Bender et al. (2004) determined that a distance section of a computer-aided design course took less time to conduct than a live section of the same course taught face-to-face if student assessment and enrollment activities were not included. When the time invested in conducting the two sections was analyzed on a per student basis, the results indicated 
that the online course time investment was higher than for the traditional face-to-face section.

Communication is another strategic barrier that must be addressed with distance education courses (Bray et al., 2007). Personal communication between students and instructors in any distance education format may be facilitated via computer-mediated communication (CMC), e-mail, and private mail provided through course platforms (Johnson and Huff, 2000; Manning, 1996). Despite enhancements in communication offered through CMC, concerns have continued to increase regarding asynchronous communication and the loss of camaraderie that occurs with distance courses (Baer, 2000; Gehlauf et al., 1991; Hiel and Herrington, 1997; Powell et al., 2008; Rovie, 2001). Dillion (1998) suggests that faculty and students would prefer direct interaction and that both groups miss synchronous communication in distance courses. IVC technology somewhat allays these disquieting aspects by providing a synchronous communication format between multiple individuals $(\mathrm{Ng}, 2001)$. Abrahamson (1998) suggested two-way, full-motion video as a method for distance courses to achieve parity with traditional courses. Contrastingly, Manning (1996) reports that students actually feel more comfortable communicating electronically as there is less peer pressure. In addition, Carswell (1997) determined that web-based instruction did not have a significant impact on self image, learning outcomes, or overall course satisfaction for distance students.

Transactional distance theory is a theoretical framework useful in studying distance education (Jung, 2001). This theory identifies three primary components to distance education: communication or interaction of teachers and students, learner autonomy such that the student makes decisions on about his/her own learning, and structure where program flexibility meets individual student needs (Moore, 1993). In this study, communication and structure components of an undergraduate distance education program in horticulture are explored. The first objective of this investigation was to analyze communication methods between students and faculty in webfacilitated, online, and IVC courses.
The second objective was to determine the time invested by faculty in course delivery, grading, student communications, and administrative activities across these three modalities of web-facilitated, online, and IVC courses. The transactional distance theory was used as the theoretical framework for this study.

\section{Materials and methods}

EXPT. 1. This investigation was conducted in two parts. During the first part of the study, multiple sections of a lower division horticulture course were used. For the study, teaching mode (online and webfacilitated) were treatments. The population consisted of 239 students enrolled in four sections of this undergraduate course. Forty-seven of the students experienced online instruction using the WebCT platform (CE 4.1; WebCT, Lynnfield, MA) and comprised two sections of the course. These students were located on and off campus, with no distinction being made to their proximity to the campus. The entire course was conducted online, with no face-to-face meetings. The remaining 192 students were divided into two web-facilitated courses sections. These students had a course website where they could access the course syllabus, control their grades, and communicate via the online communication tools. In addition, they had the e-mail address, phone number, and office location for their course instructor. No content was delivered entirely via the website. The number and type of faculty/student contacts were recorded for the duration of each course. The time periods invested in faculty activities including lecturing, grading, recording attendance, and administrative duties were collected for comparative analysis. Time invested in the development of course content or courseware was not included given that much of the materials for the web-facilitated sections were previously created and were then modified for the online sections. Only the actual time in conducting the courses, not creating the courses, was measured. Appropriate statistical tests were conducted using SPSS 15 (standard edition; SPSS, Chicago) at a $P \leq 0.05$ significance level.

EXPT. 2. In the second portion of the study, two different upper division horticulture courses offered by IVC were investigated in a similar manner to the aforementioned study. Once again, the students had a course website with the syllabus, communication tools, and grade book. They were also provided all contact information for the instructor and were encouraged to contact their lecture instructor and local class facilitator via any communication method they desired. The class facilitator ran the equipment and proctor exams, while the instructor provided all content from a distance and graded all materials. The study population included 70 undergraduate students enrolled in two upper division courses located on a campus remote from the instructor. Once again, the number of student contacts and the amount of faculty/facilitator time were tallied. Given that there were no control sections for this portion of the study and the courses were upper division rather than lower division, only descriptive statistics are provided for informational purposes.

Two of the limitations inherent in educational research are the inability to randomize and to balance the number of students in course sections. An additional limitation of this study was the students' ability to register for course sections by time, thus determining the teaching mode they would experience. Given these limitations, several steps were taken to remediate potential problems with the study. The data reported for both portions of the study were adjusted to reflect time or contact for each student in each section to ameliorate the difficulty presented with unequal sample sizes. It was not possible to randomize the students between the sections; however, this limitation was minimized given the size of the sections and that all students in each section were included in the study. Only data gathered from the lecture portion of the courses were used in this analysis. After the participating faculty informally observed contact events with students, an assumption was made that each e-mail, phone call, or other unscheduled student contact averaged $5 \mathrm{~min}$.

In an effort to address validity, the authors ensured that the course content was similar between the sections by directly reviewing the materials used. In addition, a common syllabus was adapted between the 
sections. This allowed for a direct comparison to be made while addressing systematic bias. To handle concerns of reliability, the data in both parts of the study were coded for analysis and a written guide was created to allow for and eliminate error. In addition, an independent observer was secured to substantiate the data. A random sample of 164 data entries was examined, resulting in a highly desirable $96 \%$ reliability rating.

\section{Results}

Expт. 1. A series of comparisons was conducted to test the hypothesis that there is no difference in the number of course contacts initiated by students in courses taught by different modes. All e-mails, phone contacts, and office contacts between the faculty and the students were logged. Office contacts included tutoring as well as office visits for a simple question. The results disprove this hypothesis, as the number of e-mails and phone calls for the online sections were significantly greater than for the web-facilitated sections. Given that office visits were not possible for distance students, it is not surprising that the total number of contacts for the online sections was also significantly greater than for the web-facilitated sections (Table 1).

Focusing on the amount of time required to conduct these courses, a series of one-way analyses of variance were run to test the hypothesis that there is no difference in the amount of time per day needed to conduct a course using different teaching modes. Table 2 displays the number of minutes per day, whether actually teaching that day or not, used in preparing for class (not including initial course preparation), teaching, and grading work. There were significantly fewer minutes spent per day for the online mode than for the web-facilitated mode. This is confirmed by the cumulative number of minutes for all activities involved with conducting the course being significantly less for the online mode than the web-facilitated mode. The amount of administrative time, however, did not prove to be significantly different between the two modes (Table 2 ).

Expт. 2. In the second part of the study, the number and type of contacts for the IVC courses were tallied as well as the number of minutes for the associated course tasks. The descriptive

Table 1. Comparison of the mean number and type of student-initiated student/ instructor contacts between different teaching modes in an introductory horticulture course provided on a per semester per student basis.

\begin{tabular}{lcccc}
\hline & E-mail contacts & Phone calls & Office contacts $^{\mathrm{y}}$ & Total contacts $^{\mathrm{x}}$ \\
\cline { 2 - 5 } Teaching mode & \multicolumn{4}{c}{$[$ [mean \pm SD (no./student)] } \\
\hline Online & $5.2 \pm 0.6$ & $1.5 \pm 0.1$ & $0.0 \pm 0.0$ & $6.3 \pm 1.2$ \\
Web-facilitated & $0.5 \pm 0.1$ & $0.2 \pm 0.1$ & $0.6 \pm 0.1$ & $1.4 \pm 0.2$ \\
N & 239 & 239 & 239 & 239 \\
$P$ & $0.015^{*}$ & $0.013^{*}$ & $0.000^{*}$ & $0.02^{*}$ \\
\hline
\end{tabular}

${ }^{\mathrm{z}}$ Online teaching modes included course delivery where a minimum of $80 \%$ of the content is web based while the web-facilitated mode includes courses with $1 \%$ to $29 \%$ of the course content delivered on the web.

${ }^{y}$ Office contacts include tutoring as well as students coming in to ask a simple question.

'Total contacts include other contact methods not listed in the above table unique to a specific teaching mode (i.e., course bulletin board, postings, etc.)

* Significant at $P \leq 0.05$.

Table 2. Comparison of mean minutes expended between two different teaching modes by the course instructor per teaching activity per day over one semester.

\begin{tabular}{lccccc}
\hline & $\begin{array}{c}\text { Administrative } \\
\text { duties }^{\mathrm{y}}\end{array}$ & $\begin{array}{c}\text { Teaching } \\
\text { preparation }^{\mathrm{w}}\end{array}$ & $\begin{array}{c}\text { Class } \\
\text { time }^{\mathrm{u}}\end{array}$ & Grading $^{\mathrm{v}}$ & $\begin{array}{c}\text { Total } \\
\text { activity }\end{array}$ \\
\cline { 2 - 6 } Teaching mode $^{\mathrm{z}}$ & \multicolumn{5}{c}{$[$ mean + SD (min/d)] } \\
\hline Online & $4.2+0.5$ & $3.8+0.6$ & $4.0+0.02$ & $5.0+0.5$ & $15.8+1.8$ \\
Web-facilitated & $5.1+1.2$ & $50.0+3.1$ & $20.5+1.9$ & $12.5+1.0$ & $88.1+1.4$ \\
$\mathrm{~N}$ & 4 & 4 & 4 & 4 & 4 \\
$P$ & 0.542 & $0.019^{*}$ & $0.013^{*}$ & $0.021^{*}$ & $0.014^{*}$ \\
\hline
\end{tabular}

${ }^{z}$ Online teaching modes included course delivery where a minimum of $80 \%$ of the content is web based while the web-facilitated mode includes courses with $1 \%$ to $29 \%$ of the course content delivered on the web.

'Includes nonteaching activities necessary for the functioning of the class such as attendance, posting grades, room scheduling, or securing equipment.

Includes activities directly related to delivering content such as lecturing, releasing modules, or posting assignments.

wActivities directly related to preparing to deliver content such as reviewing modules or copying handouts, but does not include actual course development or content delivery.

${ }^{\mathrm{v}}$ Activities directly related to scoring or reviewing evaluation instruments or assignments.

uTotal time incurred related to the course, including activities unique to a specific teaching mode (i.e., tutoring, office visits, electronic bulletin boards, attendance, etc.)

* Significant at $P \leq 0.05$.

statistics for this second experiment are presented in Table 3. Given that the content of these two courses was upper division in nature, a direct comparison of the means of the IVC mode could not be made with the online and web-facilitated modes explored in Expt. 1. However, a visual inspection of the data reveals the mean minutes invested by the faculty member for all activities included in the course was $\approx 100 \mathrm{~min} / \mathrm{d}$, with about half of that time directly related to teaching. The minutes invested for course preparation, grading, and administrative activities collectively were similar to the time expended teaching. Given the estimate of 5 min per contact used in the first portion of the study, only a small fraction of the time invested in the course was dedicated to CMC.

\section{Discussion}

The results presented in Table 1 reveal that the number of contacts, by phone or e-mail, increase when students have a reduced amount of direct faculty/student contact, as would be expected. It would appear that when students have less access to faculty synchronously in class, they resort to alternative methods of communication. What is of interest is the magnitude of the increase in CMC by the online students. It appears that students readily communicate with their instructor via CMC to meet their correspondence needs with the instructor. These results confirm previous studies that found an increased use of e-mail by students enrolled in online courses and highlight the need for faculty to respond to CMC from their students in a timely fashion (Carswell et al., 2000; National Center for Educational Statistics, 1998).

Similarly, Table 2 reveals that the automation included in the online teaching mode does conserve faculty time with regard to delivery. Class preparation, grading, and teaching had significantly less time invested in the online teaching mode. This is confirmed by 
Table 3. Descriptive statistics for the mean daily contacts per student per semester and the mean minutes used per day for specific tasks when conducting upper division horticulture courses via interactive video conferencing during an academic semester.

\begin{tabular}{lc}
\hline Indices & Mean $\pm \mathrm{sD}$ \\
\hline Contacts & \\
E-mails (no./student) & $2.8 \pm 0.6$ \\
Phone calls (no./student) & $0.0 \pm 0.0$ \\
Activity time & \\
$\quad$ Administrative duty & $10.6 \pm 1.2$ \\
$\quad(\min / \mathrm{d})^{\mathrm{z}}$ & $50.0 \pm 0.0$ \\
Teaching $(\min / \mathrm{d})^{\mathrm{y}}$ & \\
Class preparation & $14.4 \pm 5.1$ \\
$\quad(\min / \mathrm{d})^{\mathrm{x}}$ & $12.7 \pm 0.9$ \\
$\quad$ Grading $(\min / \mathrm{d})^{\mathrm{w}}$ & \\
Total activity time & \\
$\quad(\min / \mathrm{d})^{\mathrm{v}}$ & $97.7 \pm 1.7$ \\
\hline
\end{tabular}

${ }^{2}$ Includes nonteaching activities necessary for the functioning of the class such as attendance, posting grades, room scheduling, or securing equipment. Includes activities directly related to delivering content such as lecturing, releasing modules, or posting assignments

${ }^{\mathrm{x}}$ Activities directly related to preparing to deliver content such as reviewing modules or copying handouts, but does not include actual course development or content delivery.

wActivities directly related to scoring or reviewing evaluation instruments or assignments.

"Total time includes other activities not listed in the above table unique to this specific teaching mode (i.e. electronic bulletin boards, connection times, returning graded materials by express mail, sending and receiving faxes, or conference scheduling).

the significantly less total time expended for the online sections than for the web-facilitated sections. The magnitude of the time savings for teaching, as well as the total activities time, is of particular interest. Contrastingly, administrative time was not significantly less in either mode. This may be because each teaching mode has its own unique set of activities that must be addressed. The limited amount of time invested in these activities did not alter the significance of the online teaching mode using less total faculty time than the web-facilitated mode. When viewing the reported time savings provided by using the online teaching mode, it must be remembered the time invested in the development of the course content itself is not reflected in this analysis. It is recognized that the initial course development requires many hours of invested time, regardless of the modality. Faculty familiarity with various teaching modes also impacts that overall time invested.

Focusing on the results in the second part of the study, it becomes apparent that even when students have easy access to cell phones, they are unwilling to contact a faculty member by phone. In neither of the two IVC sections did a student contact the faculty member during the semester. This substantiates the increased use of e-mail by students enrolled in distance courses and once again reiterates the need for timely faculty response to CMC (Carswell et al., 2000; National Center for Educational Statistics, 1998).

When reviewing the number of minutes invested in the various activities in the IVC sections, a little over half of all of the minutes invested were related to actual course content delivery. Thus, any meaningful savings in time would have to be related to teaching activities themselves. IVC in and of itself does not save faculty time. The value of this instructional mode is in the ability to have synchronous communication with students who are at a remote location. It is of note that the coordination between campuses and course facilitators, as well as equipment issues and technology failures, inflated the administrative minutes invested in the course.

Distance education in any mode will be part of higher education for years to come. CMC appears to be one of the central tools to help bridge the gap between faculty and students. Students compensate for the loss of live student/faculty communication by increasing their asynchronous contact via CMC. Given this finding, it is imperative that the instructor responds immediately to any form of asynchronous contact by their students. The online modality appears to require less instructor time investment for course delivery and does not include course development. As with any teaching mode, faculty members must be accomplished with a variety of tools to achieve their desired learning outcomes. As the online teaching experience level for faculty increases, the disparity in the time required to develop a course will decrease. It is imperative that workshops to obtain online course development skills are available for faculty who are developing distance courses. In addition, course design consultants would decrease the time invested by faculty in developing the course, as well as reduce the frustration level of said faculty member. The time savings that appears to be present with the online mode of teaching also does not reflect the amount of time required update these courses as course platforms change.

\section{Literature cited}

Abrahamson, C.E. 1998. Issues in interactive communication in distance education. Coll. Stud. J. 32:33-42.

Allen, I.E. and J. Seaman. 2007. Online nation: Five years of growth in online learning. Sloan Consortium, Needham, MA.

Baer, W.S. 2000. Competition and collaboration in online distance learning. Inf. Commun. Soc. 3:457-473.

Bender, D., B.J. Wood, and J.D. Vredevoogd. 2004. Teaching time: Distance education versus classroom instruction. Amer. J. Distance Educ. 18:103-114.

Bray, N.J., M.S. Harris, and C. Major. 2007. New verse or same old chorus: Looking holistically at distance education research. Res. Higher Educ. 48:889-908.

Butler, D.L. and M. Sellbom. 2002. Barriers to adopting technology for teaching and learning. EDUCAUSE Q. 2:22-28.

Carswell, L. 1997. Teaching via the Internet: The impact of the Internet as a communication medium on distance learning introductory computing students. SIGCSE Bul. 29(3):1-5.

Carswell, L., P. Thomas, and M. Petre. 2000. Distance education via the Internet: The student experience. Brit. J. Educ. Technol. 31:29-46.

Dillion, C. 1998. Faculty rewards and instructional telecommunications: A view from the telecourse facility. Amer. J. Distance Educ. 3:35-43.

Gehlauf, D., M. Shatz, and T. Frye. 1991. Faculty perceptions of interactive television instructional strategies: Implications for training. Amer. J. Distance Educ. 5:2-7.

Herrington, D. 2006. A ten-year retrospective on the uses of videoconferencing in support of the distance learning mission at an agricultural research center within a land-grant university system. Natl. Forum Appl. Educ. Res. J. 19:1-10.

Hiel, E.R. and D. Herrington. 1997. Plausible uses and limitations of videoconferencing as a tool for achieving technology transfer. J. Ext. 35(4). 15 Aug. 2009. <http://www. joe.org/joe/1997august/rbl.php $>$.

Johnson, M.M. and M.T. Huff. 2000. Students' use of computer-mediated communication in a distance education course. Res. Soc. Work Pract. 10:519-532.

Jung, I. 2001. Building a theoretical framework of web-based instruction in the context of distance education. Brit. J. Educ. Technol. 32:525-534. 
Manning, L.M. 1996. Economics on the Internet: Electronic mail in the classroom. J. Econ. Educ. 27:201-204.

Moore, M.G. 1993. Transactional distance theory, p. 89-106. In: D. Keegan (ed.). Theoretical principles of distance education. Routledge, New York.

National Center for Educational Statistics. 1998. National survey of distance education. 7 Nov. 2002. <http://www.nces. ed.gov/pubs98/distance/index.html>.
$\mathrm{Ng}$, K.C. 2001. Using E-mail to foster collaboration in distance education. Open Learn. 16:191-200.

Paulsen, K., K. Higgins, and S. Peterson. 1998. Delivering instruction via interactive television and videotape: Student achievement and satisfaction. J. Spec. Educ. Technol. 13:59-77.

Powell, P., M. Smith, and R. Davis. 2008. Procedures that improve the interactive video: Learning environment. J. Ext.
46(3). 15 Aug. 2009. <http://www. joe.org/joe/2008june/tt7p.shtml7>.

Rovie, A.P. 2001. Building classroom community at a distance: A case study. Educ. Technol. Res. Dev. 49:33-48.

Wilson, C. 2001. Faculty attitudes about distance education. EDUCAUSE Q. 2:70-71. 